\title{
Maskulinitas dan bunga dalam karya R.M. Noto Soeroto Melatiknoppen: gedichten in proza dan De geur van moeders haarwrong
}

\author{
CHRISTINA SUPRIHATIN
}

\begin{abstract}
R.M. Noto Soeroto was one of the Indonesian writers who wrote in Dutch. His poems and essays in Dutch were well appreciated by both the Dutch and the Indonesian society in the Netherlands. He published his works in Oedaya: Majalah bergambar untuk Indonesia, a magazine (1923-1931) that was founded by him. His works can be categorized as Dutch-East Indies literature. Most of his works in Dutch were written when he lived in the Netherlands and describe the Javanese culture. This article is an analysis on three of Soeroto's poems. These three poems present flowers as theme, two poems are from his anthology Melatiknoppen: gedichten in proza (1915) and one poem from De geur van moeders haarwrong (1922). Flowers are most usually seen as a symbol for women, and thus represent the idea of femininity. However, the flowers in these three poems refer to the idea of masculinity. Jasmine is no longer a symbol limited to the feminine gender. In Javanese culture, the jasmine flower attached to the hair is a symbol of femininity. The flower wrapped around the kris is a symbol of masculinity. Furthermore jasmine is a symbol for struggle. This article tries to demonstrate the presence of masculinity through the use of flowers and their role as an image of masculinity in Noto Soeroto's poems.
\end{abstract}

KEYWORDS

Sastra Hindia-Belanda, bunga, melati, unsur Jawa, femininitas, dan maskulinitas.

Melatiknoppen: gedichten in proza (1915) dan De geur van moeders haarwrong (1922) adalah kumpulan puisi dalam bahasa Belanda karya R.M. Noto Soeroto (1888-1951) yang dapat dimasukkan dalam ranah Sastra Hindia-Belanda, meskipun penyair ini bukan orang Belanda. Isi karyanya yang membahas

CHRISTINA SUPRIHATIN adalah pengajar pada Program Studi Belanda, Fakultas Ilmu Pengetahuan Budaya Universitas Indonesia; mendapat gelar MA pada tahun 1991 dari Dutch Studies, Leiden University dengan pengutamaan Sastra Hindia-Belanda. Penelitian utamanya adalah karya-karya penulis Indonesia yang termasuk dalam Sastra Hindia-Belanda. E-mail: chris@ui.edu. 
Indonesia (dulu Hindia) dan ditulis dalam bahasa Belanda memenuhi kriteria untuk dapat dianggap sebagai karya sastra Hindia-Belanda. ${ }^{1}$

Dalam tulisan ini akan dikaji sajak-sajak dari dua buku tersebut yang memperlihatkan kehadiran bunga dalam penyajiannya. Dua sajak berasal dari Melatiknoppen: gedichten in proza dan satu sajak dari De geur van moeders haarwrong. Pengkajian ketiga sajak ini dari dua buku itu didasarkan pada dua alasan. Yang pertama, untuk melihat perbedaan dan persamaan penyajian dari ketiga sajak itu yang semuanya menampilkan bunga. Kedua, untuk mengamati apakah isi sajak-sajak yang dinuansai bunga itu dengan begitu terbatas hanya mengetengahkan tokoh-tokoh femininitas, atau justru maskulinitas muncul dalam penyajian bernuansa bunga ini.

Noto Soeroto yang dikenal sebagai esais dan penyair lahir dari keluarga bangsawan Paku Alam dari Jogyakarta. Karyanya banyak diwarnai budaya Jawa, musik, dan hubungan antara Timur dan Barat. Karya puisinya diterbitkan dalam berbagai kumpulan puisi selain kedua buku tersebut di atas juga dalam Fluisteringen van de avondwind (1917) dan De wajang-liederen (1931). Kebanyakan karyanya ditulis ketika dia berada di negeri Belanda. Berbeda dengan penulis Indonesia lain, seperti Kartini dan Soewarsih Djojopoespito, yang menulis karya-karyanya di Indonesia. Kedua nama penulis wanita itu juga masuk jajaran penulis Sastra Hindia-Belanda. Karya Noto Soeroto mendapat tanggapan hangat dari masyarakat Belanda di bagian barat Belanda, seperti Den Haag, Leiden, dan Amsterdam karena di sepanjang daerah ini banyak tinggal orang-orang Indonesia, Indo, dan Belanda yang memiliki hubungan emosional dengan Indonesia karena masa lalunya. Selain aktif sebagai penggiat sastra, nama Noto Soeroto juga dikenal dalam kancah politik. Bertahun-tahun lamanya dia menjadi ketua Indische Vereeniging, perkumpulan mahasiswa Indonesia di Negeri Belanda. Pada tahun 1923 dia mendirikan majalah Oedaya; Majalah bergambar untuk Indonesia. Melalui majalah ini ia memperkenalkan banyak karyanya. ${ }^{2}$ Hubungan antara keberadaannya sebagai penyair dengan latar belakang budayanya dan sajaknya yang ditulis dalam bahasa Belanda juga pernah dimuat dalam majalah De Revisor, majalah sastra untuk Belanda dan Flandria yang terbit dua bulan sekali. ${ }^{3}$

\section{PENGUNGKAPAN DALAM SAJAK}

Sajak sebagai salah satu ekspresi bahasa, memiliki nilai estetik. Keindahan sajak dihadirkan oleh penyair melalui cara pengungkapan. Menurut Van Boven dan Dorleijn (1999) aspek-aspek yang terkait dengan pengungkapan itu menjadi hal yang penting dalam sebuah sajak. Pengungkapan itu menjadi menarik untuk dikaji karena cara yang digunakannya sengaja 'melenceng'

\footnotetext{
Diskusi tentang pengkategorian karya-karya dalam ranah Sastra Hindia-Belanda dapat dilihat dalam Nieuwenhuys (1978: 11-17), Van Zonneveld dan Baay (1988: 9-17), Van Zonneveld (1995: IX-X), Boukema (1992: 1-19), Termorshuizen (1990: 249-256), Maier (1992: 137-144, 1996:14-30), Praamstra (1997: 257-274), dan Paasman (1999: 66-72, 2005: 163-195).

2 Mengenai artikel Noto Soeroto dalam majalah Oedaya; Majalah bergambar untuk Indonesia lihat Suprihatin (2006).

3 Lihat De Revisor 4 (November 2002): 5-7.
} 
dari yang lumrah. ${ }^{4}$ Meski seringkali melenceng, pengungkapan itu selayaknya sejalan dengan norma dan aturan yang berlaku dalam sebuah bahasa. Van Boven dan Dorleijn selanjutnya mencontohkan dua unsur yang dapat digunakan dalam pengungkapan itu, yaitu deviasi dan ekuivalensi. Deviasi dimaksudkan sebagai penyimpangan. Ekuivalensi adalah penyebutan bila terjadi pengulangan bunyi. Van Boven dan Dorleijn memilahnya dalam 7 tataran: grafis, bunyi, kata, pembentukan kata, struktur kalimat, arti, dan teks. ${ }^{5}$ Sebagai contoh ekuivalensi pada tataran struktur kalimat, Van Boven dan Dorleijn menjelaskannya dengan sebuah sajak dari Lucebert, yang dibuka dengan dua kalimat: (1) het is de aarde die drijft en rolt door de mensen 'inilah bumi yang mengambang dan menggulung manusia' dan (2) het is de lucht die zucht en blaast door de mensen 'inilah langit yang mendesah dan menghembus manusia'. Dua kalimat pembuka itu menunjukkan struktur yang paralel, yaitu masing-masing merupakan sebuah kalimat ( (1) het is de aarde dan (2) het is de lucht) dengan satu anak kalimat ((1) die drifft en rolt door de mensen dan (2) die zucht en blaast door de mensen) yang dihubungkan dengan satu kata penghubung (die). Di dalam kedua kalimat itu terdapat pengulangan het dan die. Dalam dua kalimat pembuka ini juga ditemukan deviasi. Dengan pemakaian kata-kata drijft, rolt, zucht, dan blaast (mengambang, menggulung, mendesah, dan menghembus) nuansa makna yang ditimbulkan menjadi terasa. Demikian pula dengan pemakaian aarde 'bumi' dan lucht 'langit' juga memiliki efek yang sama. ${ }^{6}$

Pemikiran Van Boven dan Dorleijn sejalan dengan yang dikemukakan oleh Feijter (1991). Feijter menggunakan peristilahan 'seleksi dan kombinasi' dan ekuivalensi. Feijter menjelaskan ekuivalensi dapat dijabarkan sebagai prinsip-prinsip yang mendasari suatu seleksi dan kombinasi. Dalam suatu sajak, ekuivalensi dapat ditampilkan dengan memilih bunyi yang serupa berturutan. Dalam hal ini ekuivalensi menjelma sebagai prinsip yang dibangun berdasarkan kombinasi berturutan. Untuk menjelaskannya Feijter meminjam kalimat pembuka dalam sajak Gorter yang berjudul Mei, yang berbunyi Een nieuwe lente / een nieuwe geluid, 'Musim semi baru / suara yang baru'. Ekuivalensi sintaktis menunjukkan lente yang diperbandingkan dengan geluid. Selanjutnya efek dari perbandingan ini bisa dijelaskan dengan memperlihatkan relasi semantis antara kedua elemen dalam sajak, antara lente dan geluid, bahwasanya interpretasi kehadiran 'musim semi' ditandai dengan 'suara-suara' (kicau burung yang baru ada di musim semi). ${ }^{7}$

Ekstra dimensi yang dihadirkan dalam sajak dapat membangun arti. Van Alphen dkk. (1996) menjelaskan ekuivalensi dapat menciptakan ekstra dimensi dalam sajak. Pengulangan bunyi, misalnya, dapat menimbulkan harmonisasi. Sebaliknya, ekstra dimensi juga dapat ditampilkan dengan menghadirkan pengulangan-pengulangan yang tidak lazim, atau bahkan yang menyalahi aturan. Menurut Van Alphen dkk., metafora dapat dipergunakan

\footnotetext{
Van Boven dan Dorleijn 1999: 44.

Van Boven dan Dorleijn 1999: 50.

Van Boven dan Dorleijn 1999: 63.

Feijter 1991: 73
} 
untuk menghadirkan makna dengan dimensi baru. Misalnya, dua objek atau situasi yang dperbandingkan. Van Alphen dkk. menjelaskan, dalam de mens een wolf is 'manusia adalah serigala', / manusia/ dan / serigala/ tidak identik. Dalam hal ini, 'persamaan' yang diketengahkan tidak menimbulkan efek sama. Batasan yang menjelaskan arti kata 'serigala' justru terlampaui. Dalam situasi ini, makna baru diciptakan: manusia (dapat) lebih kejam dari seekor serigala. ${ }^{8}$ Seringkali juga digunakan subtitusi pengganti makna. Berbagai simbol dihadirkan untuk menggantikan makna. Luxemburg (2002) mendefinisikan simbol sebagai suatu tanda yang menunjuk pada sesuatu (biasanya benda), yang mempunyai arti 'lebih' dan 'lain' berdasarkan asosiasi tertentu. Analisis substitusi pengganti makna dan simbol yang digunakan selanjutnya diharapkan dapat menunjukkan arah yang tepat menuju interpretasi.

\section{MELATIKNOPPEN: GEDICHTEN IN PROZA}

Kumpulan sajak 'Kuncupkuncup Melati; sajak dalam prosa' mengandung dua puluh empat sajak yang disajikan dalam bentuk prosa. Setiap sajak diberi nomor dan pada beberapa sajak tercantum inisial orang-orang kepada siapa sajak tersebut didedikasikan. Pada bagian akhir buku diberikan catatan-catatan bernomor berisi penjelasan kata-kata asing atau penjelasan yang berkaitan dengan hal budaya. Dari kumpulan ini dipilih dua buah sajak, sajak I dan sajak II untuk dibahas.

Sajak I ini merupakan prosa yang dituangkan melalui katakata atau pernyataan dari seseorang. Seseorang di sini disebutkan sebagai $u$ 'Anda'.

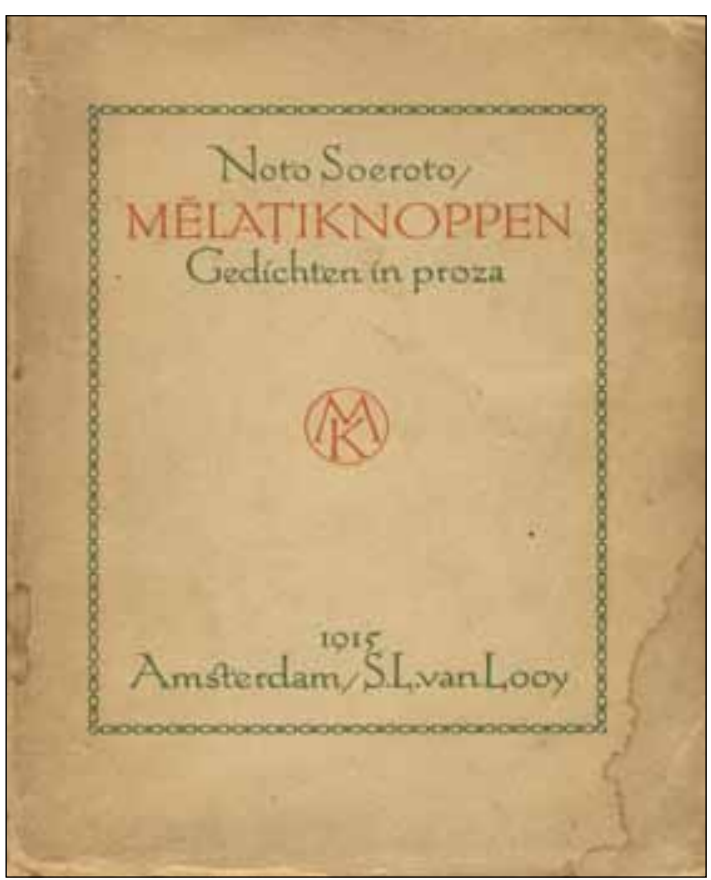

Gambar 1. Sampul buku Melatiknoppen: gedichten in proza

Pada awal sajak I ini tertera di sebelah kanan atas singkatan N.M. Diduga N.M. adalah singkatan nama kepada siapa sajak ini didedikasikan. Dalam penelitian biografi Noto Soeroto sebagai penyusun sajak tidak ditemukan nama yang dapat dikaitkan dengan singkatan tersebut. Tidak ada tanda dalam sajak ini yang memastikan bahwa N.M. adalah seorang perempuan. N.M. bagi si tokoh Aku dalam sajak memanglah figur yang dihormati dan dipuja; hal ini terlihat dengan pemakaian kata-kata hormat seperti $u$ 'Anda',

$8 \quad$ Van Alphen dkk. 1996: 137. 
$u w$ atau $u w e$ 'harafiah: milik Anda'. Bahkan pengungkapan bahwa si Aku mempersembahkan N.M. yang dipuja dengan bunga-bunga karena N.M. adalah pecinta bunga tidaklah cukup memberikan rasa dan juga bukti bahwa N.M. adalah seorang perempuan. Pilihan bunga dari si Aku sebagai bentuk persembahannya kepada N.M. juga tidak dapat dijadikan sebagai faktor penentu bahwa si Aku adalah perempuan.

Sajak I:

N. M.

N. M. ${ }^{9}$

Ik wilde u met bloemen vereeren;

$i k$ weet dat ze u lief zijn.

Zoo zocht ik naar bloemen, veelkleurig en geurig,

in den tuin van mijn eigen gedachten,

om daarvan een tuiltje te maken,

dat zich zal weerspiegelen

in 'n glimlach van uw gemoed.

Vergeefs zocht ik echter;

geen enkele bloem vond ik daar,

in den tuin van mijn eigen gedachten.

Daar kwam een vroom gezang tot mijne ooren aangewiekt

en drong tot diep in mijne ziel.

Ik spoedde me naar mijn deur en zag

een vromen zanger langs mijn lage woning lang-

zaam gaan.

Zijn schreden richtten zich naar gindschen tempel van licht

en in zijn armen droeg hij ' $n$ vracht van de heerlijkste bloemen,

die mijn huis met 'n zoeten geur veroulden.

De bloempjes, die den armen des zanger waren ontslipt,

die had ik opgeraapt

en bond ze sâam tot een schuchter tuiltje.

Dit leg ik voor u neer, opdat ik moog' genieten van ùwe vreugde om bloemen uit dichter-levenshof.

\author{
Aku ingin menganugerahimu bunga: \\ aku tahu kau menyukainya. \\ Maka aku cari bunga, aneka warna dan aroma \\ di taman anganku, \\ untuk kujadikan buket kecil, \\ yang akan tercermin \\ dalam senyum perasaanmu. \\ Tapi sia-sia aku mencari, \\ tak sekuntum bunga pun kutemukan di sana, \\ di taman anganku.
}

\begin{abstract}
Sebuah tembang suci menyentuh telingaku

dan menembus relung hatiku

Kubergegas ke pintu dan melihat

seorang penembang saleh perlahan melintasi rumahku

Langkahnya menuju pura cahaya di sebelah sana

dan di tangannya dia menyandang serangkai bunga paling semerbak,

yang aroma manisnya memenuhi rumahku.
\end{abstract}

\footnotetext{
Bunga-bunga, yang terlepas dari tangan sang penembang,

kupunguti

dan kurangkai menjadi satu buket sederhana.

Kupersembahakn buket itu kepadamu, agar aku dapat menikmati kegembiraanmu melihat bunga dari taman-kehidupan-penyair.
}

Maskulinitas juga lebih tampak jelas dalam sajak ini melalui tanda-tanda bahasa yang dipakai. Kata zanger dalam bait kedua baris kelima dan bait ketiga baris pertama mengandung sufiks -er yang menandai aspek maskulin. Di sini penembang itu adalah laki-laki. Dalam bait kedua baris kesembilan (in zijn armen droeg hij 'n vracht van de heerlijkste bloemen 'di tangannya ia menyandang serangkum bunga-bunga yang paling harum semerbak') maskulinitas ini lebih ditegaskan lagi oleh penggunaan subjek hij, kata ganti orang ketiga laki-laki, dan penggunaan kata zijn, kata ganti milik orang ketiga laki-laki.

Bunga dalam sajak berbentuk prosa ini menempati posisi sentral dalam keseluruhan pengisahan cerita. Bunga adalah bentuk persembahan si Aku kepada orang yang dipuja. Bunga adalah sesuatu yang dicintai oleh yang dipuja si Aku. Bunga adalah pantulan ungkapan hati. Bunga melambangkan

$9 \quad$ Terjemahan ini didasarkan semata-mata pada kebutuhan pemahaman makna sajak. 
keharuman, keindahan, kebahagiaan, dan keasrian yang dirasa. Pada akhirnya bunga diberikan simbol yang tinggi sebagai bunga yang berasal dari taman kehidupan penyair. Bunga mengandung makna yang lebih dalam daripada arti sebenarnya tetapi bunga di sini tidaklah tampak menyimbolisasikan gender tertentu. Baik femininitas maupun maskulinitas tidaklah tersirat melalui lambang bunga ini. Sajak yang justru ditandai dengan pemakaian bunga dalam pemaparan kisahnya ternyata mengandung aspek-aspek maskulin. Sajak I ini secara grafis memperlihatkan ciri umum yang dimiliki sajak. Meski berbentuk sebuah prosa, bentuk umum sajak masih dipertahankan. Bentuk prosa memungkinkan sajak ini tidak memiliki rima yang beraturan. Sajak terdiri dari tiga bait, jumlah baris dalam setiap bait tidak sama. Bait pertama terdiri dari tiga kalimat yang disajikan dalam sepuluh baris, bait kedua tiga kalimat dalam sebelas baris, yang terakhir dua kalimat dalam tujuh baris. Dalam bait pertama rimanya sebagai berikut, 1. -en, 2. zijn, 3. -ig, 4. -en, 5. -en, 6. -en, 7. -moed, 8. -er, 9. daar dan 10. -en.

Dari segi bunyi dalam sajak ini hadir pengulangan (Feijter 1991, Van Boven dan Dorleijn 1999). Pengulangan muncul di ketiga bait. Persamaan bunyi vokal ditemukan pada:

bait 1 , baris 1 : bloemen---vereeren

bait 2, baris 3: veelkleurig---geurig

bait 2, baris 2: diep---ziel

Pengulangan konsonan ditemukan pada:

bait 1, baris 3: zoo---zocht dan glimlach---gemoed

bait 2, baris 1: kwam---vroom

Pengulangan pada tataran kata ditemukan pada kata-kata berikut:

bait 1, baris 1, 3 dan 9: bloem/bloemen

bait 1 , baris 3, 8: zocht

bait 1 , baris 4,10 : tuin

bait 2, baris 1, 3: vroom/vromen

bait 3, baris 1, 6: bloempjes/bloemen

Beberapa kata yang telah dimunculkan pada bait pertama ditemukan kembali pada bait kedua dan ketiga. Kata-kata yang diungkap pada bait kedua juga hadir di bait ketiga (bloemen, tuiltje, armen, zanger).

Pengulangan juga terjadi pada tataran kalimat. Pada bait pertama, kalimat in den tuin van mijn eigen gedachten dari baris keempat diulang pada baris terakhir. Harmonisasi yang timbul dengan pengulangan kalimat beresensi ini sesuai dengan pemikiran Van Alphen dkk. (1996).

Efek puitis dan estetis yang tercipta berkat pilihan kata seperti pendapat Feijter (1991) juga ditemukan dalam sajak ini. Pengungkapan perasaan disajikan dengan penggunaan kata bunga. Bunga sebagai persembahan kepada orang yang dijunjung tinggi dan bunga sebagai sesuatu yang disukai. Dalam bait kesatu si Aku ingin mempersembahkan bunga kepada seseorang yang dipujanya, dan seseorang ini menurut si Aku adalah pecinta bunga. Bunga memiliki beragam makna puitis, seperti yang dinyatakan oleh Luxemburg (2002). Makna yang sama diungkap dengan kata yang berbeda pada bait 
kedua. Bunga dalam rangkulan penembang yang saleh adalah rangkaian dari jenis bunga dengan aroma yang sangat wangi. Bunga menjadi simbol benda yang bernilai tinggi untuk menunjukkan perasaaan yang dalam terhadap orang yang dijunjung tinggi, dihormati, dicintai, dan dipuja.

\section{Sajak II:}

R.A.K.

Den avond voordat ik vertrok naar vreemde landen, zuster,

heb ik een hoekje van ons kleinen tuin een melati-struik geplant.

"ja, zorg er goed voor", zoo sprak ik, "dit zij u mijn gedachtenis".

Als deze bloemen, wèl zal 't mij dan gaan".

Jaren daarna schreef ge me dat 't struikje vol zat van kleine, witte knoppen.

Zoo hebt ge dan goed het teere plantje gekweekt, met zorgvolle handen.

's Morgens plukt ge de bloemen af om kwistig

ze op ' $t$ bed van moeder te strooien.

Zuster, mogen even heerlijk bloeien de melati's in mijn eigen hart.

Ze wachten nog op de frischeid

van

zulk koele, zachte handen.

Ze wachten op de warme stralen

van koesterende zonne-oogen.

Als ik teruggekeerd zal zijn van vreemde landen, zullen we van de melati's uit ons eigen tuin slingers rijgen

met kantil-bloemen als franjes aan de einden.

Ook zullen wij van bloemen netten weven.

Wie zal echter om den haarwrong

het net van bloemen dragen, als een slinger van melati's mijn kris-knop siert?
R.A.K

Di malam sebelum aku berangkat ke negeri asing, saudara perempuanku,

aku sudah tanami pojok kebun kita yang kecil perdu melati.

"rawatlah dengan baik', demikian kataku, "tumbuhan ini kenanganku untukmu".

Bagai bunga-bunga inilah, keadaanku".

Beberapa tahun kemudian kau tulis kabar bahwa perdu itu telah dipenuhi kuncup-kuncup putih yang kecil.

Pastilah engkau telah merawatnya dengan baik, dengan tangan penuh kasih sayang.

Pada pagi hari kau petik bunga-bunga itu untuk ditaburkan di peraduan bunda

Saudara perempuanku, semoga melati semerbak berkembang dalam hatiku.

Tanaman itu masih menanti kesejukan

dari

tangan-tangan dingin yang lembut.

Tanaman itu menanti pancaran hangat

sinar surya yang penuh kasih.

Bila aku kembali dari negeri asing,

akan kita rangkai bunga melati dari kebun kita sendiri menjadi untaian

dengan bunga kantil sebagai jumbai ujungnya. Juga akan kita untai jaring bunga.

Tapi siapa yang akan mengenakan jaring bunga melati di sanggulnya, bak juntaian melati menghias gagang kerisku?

Seperti halnya dengan sajak I, sajak II ini dicirikan oleh kehadiran bunga. Hanya dalam sajak II diketengahkan jenis bunga yang lebih khusus, yaitu bunga melati. Demikian pula dengan sajak ini yang juga merupakan pernyataan dari si Aku kepada seseorang. Jika dalam sajak I seseorang itu mengacu pada $u$ 'Anda' maka di dalam sajak II seseorang itu adalah zuster. Kata ini dapat memiliki tiga makna; 1. kakak atau adik perempuan, 2. suster perawat, dan 3. suster biarawati. Sajak prosa ini mengisahkan keberangkatan si Aku ke negeri asing dengan meninggalkan perdu melati yang baru ditanam di kebunnya; dikabarkanlah bahwa tanaman melati itu dipenuhi dengan kuncup-kuncup bunganya yang kecil-kecil dan putih-putih berkat tangan yang telaten dan penuh kasih sayang memeliharanya dengan baik; di pagi hari bunga-bunga itu dipetik untuk ditaburkan di ranjang bunda; hingga suatu ketika si Aku kembali maka melati itu pun dapat dipetiknya dan dirangkainya 
bersama dengan kantil untuk hiasan jaring sanggul seperti untaian melati yang melilit keris si Aku. Dengan menelusuri seluruh kisah yang diutarakan si Aku maka dapat ditarik suatu tali hubungan cerita bahwa zuster dalam sajak I ini dapat dikaitkan dengan makna pertamanya, yaitu kakak atau adik perempuan dari si Aku. Si Aku berpesan kepada saudara perempuannya untuk memelihara tanaman melati itu dengan baik-baik karena disebutkan bahwa seperti keadaan bunga-bunga melati itu demikian pulalah nantinya keadaan si Aku di negeri asing. Di sini tidak ditemukan tanda yang dapat menjelaskan apakah zuster ini adalah memang betul saudara perempuan yang lebih tua dari si Aku (kakak perempuan) atau yang lebih muda (adik perempuan).

Dalam sajak II ditemukan singkatan R.A.K. yang tertera di awal dan bagian kanan sajak. R.A.K ini diduga merupakan singkatan dari Raden Ajeng Kartini, sosok wanita yang ketegarannya dan perjuangannya memberi insipirasi Noto Soeroto. ${ }^{10}$ Kemungkinan alasan ini pulalah yang membuat Noto Soeroto memakai kata melati dalam sajaknya karena melati dalam konsep budaya Jawa menyimbolisasikan perjuangan. Jika demikian, zuster bisa saja bukan diartikan sebagai adik atau kakak perempuan si Aku tetapi dalam konteks ini lebih tepat untuk diinterpretasikan sebagai kata sapaan untuk orang yang lebih tua atau yang dihormati, yang secara emosional memiliki "kedekatan" dengan si Aku.

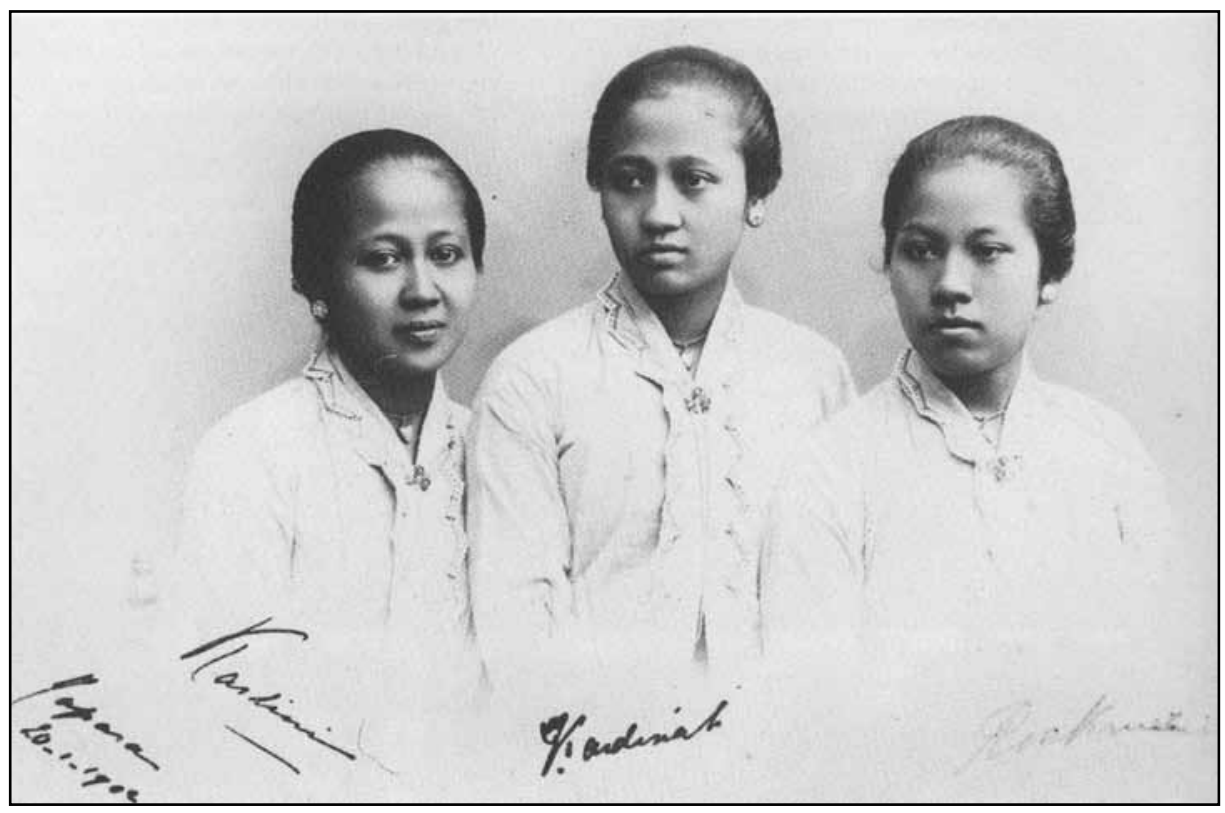

Gambar 2. Foto R.A. Kartini (kiri) bersama dua orang saudara perempuannya (sumber: Nieuwenhuys 1998: 100)

10 Lihat pidato pembukaan yang disampaikan Noto Soeroto dalam Kongres Indische Vereeniging di Den Haag, 24 Desember 1911 yang berjudul De gedachten van Raden Adjeng Kartini als richtsnoer voor de Indische Vereeniging. 
Sajak II ini secara grafis juga memperlihatkan ciri umum yang dimiliki sajak. Bentuk puisi masih dipertahankan. Tidak ditemukan rima yang teratur. Sajak terdiri dari lima bait, jumlah baris dalam setiap bait tidak sama. Bait pertama terdiri dari tiga kalimat disajikan dalam tujuh baris, bait kedua tiga kalimat dalam enam baris. Bait ketiga terdiri dari tiga kalimat disajikan dalam enam baris, bait ke empat dua kalimat dalam lima baris. Bait yang terakhir terdiri dari satu kalimat disajikan dalam terbagi dalam tiga baris. Persamaan bunyi vokal dan konsonan ditemukan pada:

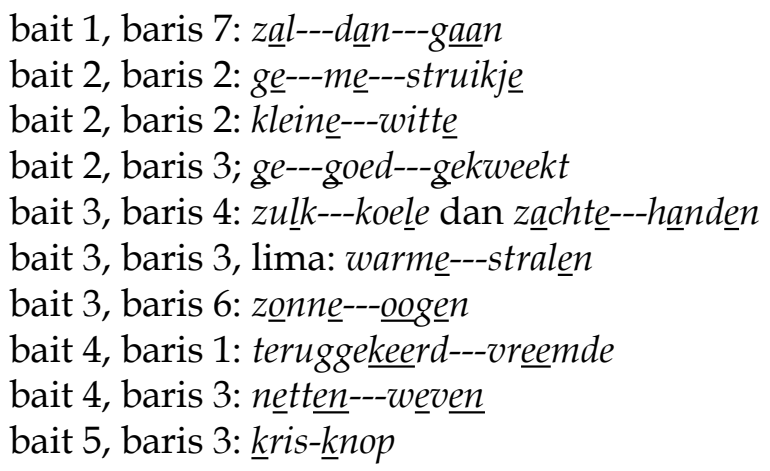

Pengulangan pada tataran kata ditemukan di setiap bait. Kata melati muncul pada bait satu sampai lima dalam berbagai variasi. Pada bait pertama sebagai melati-struik 'perdu bunga melati', yang setelah beberapa tahun sarat dengan kuncup bunga putih kecil. Pada bait ketiga melati hadir sebagai 'bunga yang mekar'... bloeien de melati's. Dan pada bait keempat dan terakhir bunga melati dipetik dan dirangkai bersama bunga kantil menjadi jaringan bunga yang akan disematkan pada sanggul dan keris.

Ekuivalensi pilihan kata dihadirkan melalui asosiasi yang dikaitkan antara melati dan kesederhanaan (Luxemburg 2002; Van Alphen dkk. 1996). Pada bait perdu bunga melati ditanam di 'taman yang kecil'; pada bait kedua melati dikatakan sebagai het teere plantje 'tumbuhan kecil yang lemah'. Meski kecil dan ringkih, di tangan yang tepat melati bisa menjelma menjadi bunga yang bermanfaat. Pada bait kedua goed gekweekt met zorgvolle handen, 'dirawat baik oleh tangan yang penuh kasih sayang'. Pada bait ketiga Ze wachten op de frischheid van zulk koele, zachte handen 'melati menantikan kesejukan tangantangan dingin dan lembut yang dapat merawatnya'.

Berbeda dengan sajak I, di dalam sajak II ditemukan pelbagai tanda yang memarkahi kehadiran perempuan. Makna kata-kata berikut mengacu langsung pada aspek perempuan: kata zuster di bait kesatu baris kedua dan di bait ketiga baris kesatu dan kemudian kata moeder 'bunda', di bait kedua baris keenam. Selain itu, kata haarwrong 'sanggul' mengimplikasikan kehadiran perempuan. Asosiasi kehadiran perempuan dapat juga ditelusuri melalui interpretasi makna dalam bait ketiga dan simbolisasi melalui pemakaian frasa seperti ... de frischheid van zulk koele, zachte handen. ... op de warme stralen van koesterende zonne-oogen '... kesejukan tangan-tangan yang begitu halus 
lembut. ... pancaran hangat dari surya yang penuh kasih'. Makna bait ketiga ini dapat diinterpretasikan sebagai: si Aku seakan-akan menunggu kehadiran perempuan dalam hatinya. Asosiasi kehadiran perempuan ini berlanjut dalam kedua bait berikutnya: bait keempat dan kelima sebagai penutupnya. Interpretasi makna bait kedua itu adalah bahwa si Aku sekembalinya dari negeri asing mengajak saudara perempuannya untuk meronce melati-melati yang dipetiknya dari kebun sendiri itu bersama kantil, menjadikannya untaian bunga; siapakah nantinya yang memakai jaring rambut beruntai bunga di sanggulnya seperti untaian melati yang melilit menghiasi gagang keris si Aku? Dalam sajak II ini maskulinitas justru dipersonifikasikan oleh si Aku. Mijn kris-knop 'gagang kerisku' menandai si Aku sebagai laki-laki.

\section{DE GEUR VAN MOEDERS HAARWRONG}

Kumpulan sajak De geur van moeders haarwrong 'Wanginya sanggul ibu' didedikasikan Noto Soeroto kepada R.M. Noto Diningrat, kakak laki-lakinya. Ada 25 sajak dalam kumpulan itu dan setiap sajak mempunyai judul. Dari kumpulan ini dipilih sajak dengan judul Moeders haarwrong 'Sanggul ibu' untuk dikaji.

Sama seperti kedua sajak sebelum ini, dalam sajak berjudul Moeders haarwrong 'Sanggul ibu' ini bunga juga muncul. Seperti halnya dengan sajak II dari kumpulan puisi Melatiknoppen: gedichten in proza, bunga melatilah yang ditampilkan.

Sajak ini memperlihatkan ungkapan perasaan pemujaan peran ibu oleh si Aku yang dituangkan dalam dua bait. Seperti halnya dalam sajak I, bunga merupakan wujud yang

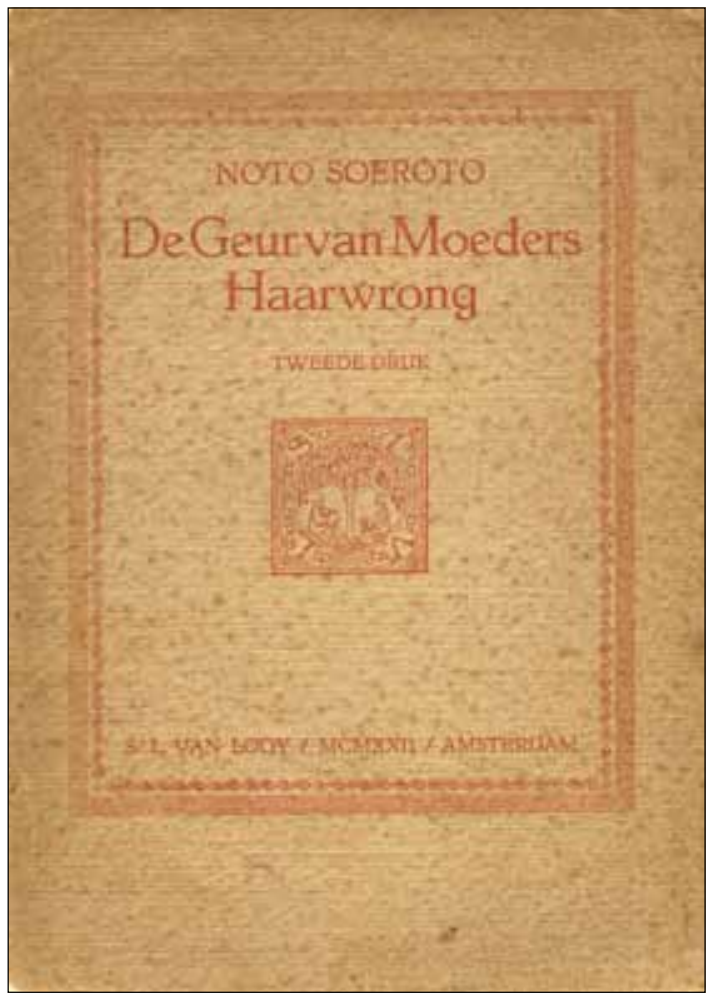

Gambar 3. Sampul buku De geur van moeders haarwrong menjembatani antara si Aku dengan orang yang dijunjungnya, dalam hal ini adalah ibunya. Bunga merupakan bentuk persembahan si Aku. Pada bait dua baris satu dan dua tersirat bahwa si Aku ingin merangkai bunga-bunga melati itu pada suatu benang sutra untuk dapat disematkan di sanggul ibunya. Melati adalah tanda ungkapan hati si Aku terhadap ibunya. Melati juga menandai kedekatan fisik dan emosi antara si Aku dan ibunya. Keharuman wangi dan kelembutan bunga melati (bait kedua, baris lima: uw armen teeder geslagen, 
omwaden ons de geuren zoet en zacht'tangan ibu memelukku halus, menyelimuti aroma manis dan lembut kita', dapat diinterpretasikan menuansai kenangan semasa kecil si Aku (bait dua, baris 3-4).

Moeders haarwrong

O moeder, zichtbaar zal het teeken wezen, waarmee ik u mijn morgenvreugde dank. In 't woud verscholen, nauw omhoog gerezen, daar staat uw mlati-struikje klein en rank. Met water uit den breeden, klaren stroom begiet ik't frisch in morgenzonnegloed, opdat de knoppen dra met schuchtren schroom des middads opengaan in lichte-groet. Ik beid den bloementooi in stil verlangen: want spoedig komt de nacht, zoo, diep, zoo breed, die al, wat is van zonnevreugd bevangen, omhult met sluiers van zijn donker kleed.

\section{' $k$ Wil bloemen rijgen aan een draad van zijde,} die ge in uw haar-wrong kunt verborgen dragen. Als we des avonds slapen gaan, wij beiden, uw armen teeder om mij heen geslagen, omwaden ons de geuren zoet en zacht. Zij maken ons den sluimer tot een bood van nooit geziene droomen diep in nacht, die ons het Licht verbergt in duistren schoot. Ik beid den bloementooi in duldloos bangen: misschien is daar de storm in aantocht reeds, die al wat is van levensvreugd bevangen, omsluiert ras met't waas se doode kleeds.
Sanggul ibu

Ibu, nampaklah tetanda itu saat aku mensyukuri kegembiraan pagiku.

Tersembunyi dalam rimbun, merambat ke atas, perdu melati tampak kecil dan ringkih.

Dengan air dari arus yang jernih

kusirami kesegaran dalam sinar surya pagi,

agar kelopak sgra membuka perlahan

bersama sinar siang salam-terang.

Kurangkai bunga dalam kerinduan terpendam: karena malam segera datang, begitu mencekam, menguasai, semua, yang tertawan dalamkegembiraan surya terselubung selaput kegelapan.

Kuingin merangkai bunga pada seutas benang sutra,

yang dapat disemat tersembunyi di sanggul ibu.

Bila malam kita tidur, kita berdua,

tangan ibu memelukku halus, menyelimuti aroma manis dan lembut kita.

selimut yang membuat kita hanyut dalam mimpi yang tak pernah terlihat di malam gelap,

yang menyimpan bagi kita Cahaya dalam pangkuan kegelapan.

Kurangkai bunga dalam kegamangan;

mungkin badai segera datang,

yang menawan semua kegembiraan hidup,

akan segera menyelubungi dengan kabut kain kematian.

Seperti di dalam sajak II, bunga melati dalam sajak ini diketengahkan dalam kaitannya dengan sanggul. Melati dirangkai untuk disematkan di sanggul. Di sini tercermin gambaran perempuan dalam budaya Jawa. Dalam sajak ini bunga hanya dikaitkan dengan sosok perempuan. Tidak ada tandatanda yang ditemukan memarkahi kehadiran sosok laki-laki. Maskulinitas hanya diinterpretasikan berdasarkan keseluruhan makna sajak dan melalui kehadiran sosok si Aku.

Sajak ini memperlihatkan ciri umum puisi. Sajak terdiri dari dua bait yang masing-masing disajikan dalam dua belas baris. Rima sajak a b a b, misalnya pada bait satu ditemukan rima -en dan -ank (baris 1-4); -oom dan -oed/t (baris 5-8), -en dan -eed (baris 9-12).

Dalam sajak ini efek harmonisasi seperti yang disebutkan Van Alphen dkk. (1996) dicapai dengan melakukan pengulangan bunyi vokal dan konsonan. Pengulangan misalnya ditemukan pada:

bait 1 , baris 1: teeken---wezen

bait 1, baris 4: daar---staat

bait 2, baris 1: riiggen---zijde 
bait 2, baris 2: verborgen---dragen

bait 2, baris 1: ras---waas

Pengulangan konsonan ditemukan pada:

bait 1, baris 1: zichtbaar---zal---wezen dan zoo diep---zoo breed

bait 2, baris 5: zoet en zacht

Seleksi dan kombinasi yang terkait dengan budaya Jawa memberikan efek puitis dan estetis. Seperti yang lazimnya digambarkan dalam budaya Jawa, kesederhanaan dan kebersahajaan lebih diutamakan justru untuk memperlihatkan sesuatu yang besar dan lebih tinggi. Dalam sajak ini seleksi terlihat melalui pilihan kata dan frasa, misalnya kata mlati-struikje 'perdu melati', dipilih dengan menggambarkannya sebagai rumpun tersembunyi di dalam kelebatan (bait 1, baris 3-4). Dengan sufik -je pada kata struikje menyiratkan' kecil' yang dapat diinterpretasikan sebagai ungkapan keakraban dan kesederhanaan. Hal ini lebih ditegaskan lagi dengan pemakaian kata-kata berikutnya klein 'kecil' dan rank'kurus ringkih'. Selain itu, ditemukan pilihan kata verscholen 'tersembunyi' (bait satu, baris tiga) dan verborgen 'tak nampak' (bait dua, baris dua) yang memperkuat simbol kebersahajaan. Berangkat dari titik ini menuju penggambaran sesuatu yang besar dan berkembang. Berkat air dan bersamaan dengan datangnya cahaya pagi maka kuncup-kuncup melati itu mekar (bait satu, baris 5-8). Sama seperti proses berkembangnya dari sesuatu yang kecil menjadi besar, seperti pada pertumbuhan tanaman melati, maka dalam sajak ini juga terlihat proses dari terang menuju gelap. Seperti dapat dilihat baik dalam bait satu (baris 11-12) maupun bait dua (baris delapan, baris 11-12).

Ada perbedaan cara penulisan, jika dalam sajak II ditulis melati dengan huruf tegak, pada sajak ini ditulis mlati (tanpa-e) dengan huruf miring. Penulisan mlati dengan huruf miring ini kemungkinan dimaksudkan untuk menekankan pentingnya peran bunga ini.

Seperti dalam sajak II ditemukan pelbagai tanda yang memarkahi kehadiran perempuan. Makna kata-kata seperti moeder, haarwrong mengacu langsung pada aspek perempuan. Maskulinitas hanya dihadirkan dengan keberadaan si tokoh Aku, dan dalam frasa zijn donker kleed'selimut kegelapannya' terdapat aspek penanda maskulin zijn (-nya) yang dalam bahasa Belanda menandai kata ganti orang ketiga laki-laki.

\section{KESIMPULAN}

Dalam tiga sajak Noto Soeroto yang dikaji ini, bunga jelaslah memainkan peran utama. Dalam sajak I dari kumpulan puisi Melatiknoppen: gedichten in proza bunga yang diketengahkan tidak memperlihatkan spesifikasi bunga tertentu. Dalam sajak II dari kumpulan yang sama, pilihan dijatuhkan pada bunga melati. Satu sajak yang dikaji dari kumpulan puisi De geur van moeders haarwrong mengetengahkan bunga melati dan kantil. Bunga melati khususnya, yang dalam budaya Jawa kerap muncul dalam peristiwa penting di kehidupan sehari-hari, seperti misalnya dipakai sebagai asesoris sanggul dan keris, dan 
sebagai bunga yang ditabur di peraduan ataupun pusara, dalam ketiga sajak Noto Soeroto ini dikaitkan tidak hanya dengan sosok perempuan. Pada sajak I di samping bunga dikaitkan dengan aspek femininitas, juga jelas memiliki kaitan dengan elemen maskulinitas. Demikian pula pada sajak II, femininitas dipadukan dengan maskulinitas melalui pemaparan melati sebagai hiasan sanggul dan asesoris gagang keris.

Bunga yang kerap kali dihubungkan dengan keberadaan sosok perempuan, dalam ketiga sajak itu tidaklah semata-mata menjadi dominasi simbol femininitas karena pengungkapan tentang maskulinitas ternyata juga dinuansai dengan pemakaian kata bunga dan melati. Demikianlah, bunga melati bukanlah simbol yang terbatas pada gender perempuan. Dalam sajak II melati bahkan juga dikaitkan dengan simbol perjuangan, melati dalam hubungannya sebagai jaring untaian penghias sanggul memang dilihat sebagai simbol perempuan tetapi bunga melati yang dironce menjadi untaian yang menghiasi keris merupakan asesoris laki-laki. Dalam hal ini ajakan untuk bersama merangkai melati yang dipetik dari kebun sendiri, dapat dimaknai sebagai simbol ajakan untuk bersama-sama berjuang.

\section{DAFTAR PUSTAKA}

Boukema, H.J. 1992. 'Indisch-Nederlandse Letterkunde', Neerlandica Extra Muros XXX/1 (Februari): 1-19.

Feijter, Anna 1991. "Poëzieanalyse", di dalam: Peter Zeeman (ed.), Literatuur en context; Een inleiding in de literatuurwetenschap. Nijmegen: SUN

Luxemburg, Jan van. 2002. Inleiding in de literatuurwetenschap. Cetakan revisi. Muiderberg: Coutinho. (Cetakan pertama tahun 1981).

Maier, Henk 1992. 'Is Indisch-Nederlandse literatuur ook een Aziatische literatuur', Indische letteren 7/4 (Desember): 137-144.

Maier, Henk 1996. 'Indische Literatuur. Bezinnige op een definitie', di dalam: Theo L. D'haen (ed.), Weer-werk; Schrijven en terugschrijven in koloniale en postkoloniale literaturen, hlm. 14-30. Leiden: Vakgroep Talen en Culturen van Zuidoost-Azië en Oceanië, Universiteit Leiden. (Semaian no. 15).

Nieuwenhuys, Rob. 1978. Oost-Indische spiegel; Wat Nederlandse schrijver en dichter over Indonesië hebben geschreven vanaf der eerste jaren. Cetakan ketiga. Amsterdam: Querido. (Cetakan pertama tahun 1972).

Nieuwenhuys, Rob. 1998. Met vreemde ogen: tempo doeloe; Een verzonken wereld: fotografische documenten uit het oude Indië 1870--1920. Amsterdam: Querido.

Paasman, Bert. 1999. 'Grenzen en grenscorrecties in de Indisch-Nederlandse literatuur', Indische letteren 14/2 (Juni): 66-72.

Paasman, Bert. 2005. 'De muze buitengaats: een heroriëntatie op de IndischNederlandse dichtkunst', Indische letteren 20/3 (September): 163-195.

Praamstra, Olf .1997. 'De omstreden bloei van de Indisch-Nederlandse letterkunde', Tijdschrift voor de Nederlandse Taal- en Letterkunde 113-3: 257-274. 
Soeroto, Noto. 1912. De gedachten van Raden Adjeng Kartini als richtsnoer voor de Indische Vereeniging: rede, voor de Indische Vereeniging op de vergadering van 24 december 1911 te 's-Gravenhage. Den Haag: Indische Vereeniging.

Soeroto, Noto. 1915. Melatiknoppen: gedichten in proza. Amsterdam: S.L. van Looy.

Soeroto, Noto. 1917. Fluisteringen van den avondwind. 's-Gravenhage: Adi Poestaka.

Soeroto, Noto. 1918. Bloemenketenen. Amsterdam: S.L. van Looy.

Soeroto, Noto. 1922. De geurvan moeders haarwrong. Cetakan kedua. Amsterdam:

S.L. van Looy. (Cetakan pertama tahun 1916).

Soeroto, Noto. 1931. Wayang-liederen. 's-Gravenhage: Adi Poestaka.

Soeroto, Noto. 2002. 'Hollandse gedichten en Javaansche gedachten', De Revisor; Twee mandelijks literair tijdschrift voor Neerland en Vlaanderen 29/4 (November): 5-7.

Suprihatin, Christina. 2006. “Oedaya: de zonsondergang van R.M. Noto Soeroto" , di dalam: Eliza Gustinelly dkk., Tiga puluh lima tahun studi Belanda di Indonesia; Vijfendertig jaar studie Nederlands in Indonesië, hlm. 4453. Depok: Fakultas Ilmu Pengetahuan Budaya, Universitas Indonesia.

Termorshuizen, Gerard.1990. 'De Indische belletrie: een exotisch stiefkind binnen de literatuurgeschiedenis', di dalam: Traditie en Progressie. Handelingen van het Veertigste Filiologen Congres, hlm. 249-256. 'S-Gravenhage: SDU.

Van Alphen, Ernst, Lizet Duyvendak, Maaike Meyer, dan Ben Peperkamp. 1996. Op poetische wijze; Handleiding voor het lezen van poëzie. Bussum/ Heerlen: Coutinho, OU.

Van Boven, Erica dan Gillis Dorleijn. 1999. Literair mechaniek. Bussum: Coutinho.

Van Zonneveld, Peter. 1995. Album van Insulinde; Beknopte geschiedenis van de Indisch-Nederlandse literatuur. Amsterdam: Amsterdam University Press. Van Zonneveld, Peter dan Reggie Baay. 1988. Indisch-Nederlandse literatuur; Dertien bijdragen voor Rob Nieuwenhuys. Den Haag: HES. 